\title{
Study the behavior of the Distribution Network with the Application of Statcom Device
}

\author{
Abdul-Jabbar Fathel Ali \\ Professor Dr. Eng. Wasit / University
}

\begin{abstract}
Recently it has been focused on the behavior of the of distribution networks especially from power quality side because of disturbances caused by the non-linear loads, Increase in the number of electronic devices and growth of renewable energy sources. Power quality measures the efficiency of electric power transmitted from generation to the industrial, domestic and commercial consumers. At least $50 \%$ of power quality problems are of voltage quality type. In a power system voltage sags and voltage distortion introduced by harmonics are considered to be the most severe affecting power quality, because of both utilities and consumers are affected by these disturbances. These problems could be solved by: design equipment's and electrical systems to prevent electrical disturbances from causing equipment's or systems to malfunction, Analyze the symptoms of a power quality problems to determine its causes and solutions, study the medium that is transmitting the electrical disturbance and eliminate or reduce the effect of that medium. Treat the symptoms of the power quality problems by using the power conditioning device and custom power device. The presents work considers the power quality problems such as, sags, swells, harmonics, voltage interruptions and transients. A techniques which are of two categories power conditioning devices and custom power devices are investigated and the results showed that the second method is the most efficient and effective method to solve the power quality problems and protect the sensitive loads from power disturbances. The modeling and simulation of a power distribution network is achieved using MATLABL/Simulink. Three phase fault and double line to ground fault are created with the proposed system, and the faults are initiated at a duration of $0.8 \mathrm{sec}$ till $0.95 \mathrm{sec}$. Comparison the power quality problems with and without custom power device are presented with the help of Dynamic Voltage Restorer (DVR).
\end{abstract}

\section{Keywords}

Distribution Network, Power Quality, Statcom, Sags, Swells, Harmonics.

\section{INTRODUCTION}

Electrical power distribution is the main element that required in any function in the commercial and industrial sectors therefore it should be available at all times. Power quality is a set of parameters that define the characteristics of the power supply as delivered to the consumers in normal operating conditions in terms of continuity of supply and characteristics of voltage such as, frequency, magnitude, waveform and symmetry. Recently, power quality is not only a technical problem but also a problem that leads to financial issues. Many surveys have been shown that poor power quality causes large economic losses to industrial sectors. Moreover, large amount of power is wasted due to poor power quality in the services. A survey conducted to assess economic impact of poor power quality faced by various Indian industries by Emerson group and manufacturers' association for information technology (MAIT) states the estimated loss in India is close to 10 Billion USD in direct losses due to poor power quality and operating environment related to downtime. Awareness among the industries regarding the power quality should be created which helps in the increase in productivity and Gross Domestic Product (GDP) growth. PQ events are unpredictable but they can be anticipated. Determining the exact problems requires sophisticated electronic test equipment but the symptoms such as equipment failure during lightning and thunder storm, tripping of circuit breakers without being overloaded, automated system stopping for no apparent reason, electronic system failure on a frequent basis and also working of electronic system in one location but not in another location, help us to identify the PQ problems[1]. The power quality is Gaining importance from the following reasons: power electronic devices and developed equipment with microprocessor based controls are more sensitive to power quality variations, the use of power electronic devices based control of variable speed drives and switched mode power supplies creates a lot of electrical disturbances into the supply system[1]. the statistical aspects of the power quality problems as identified a number of surveys are shown in fig.1. From this figure the most common causes of disturbances at customers side are: Faulty equipment and Improper grounding to protect against surge, while the most common disturbances at utility side are caused by: Sags and swell. And the most common affected equipements are: Computers and UP. 


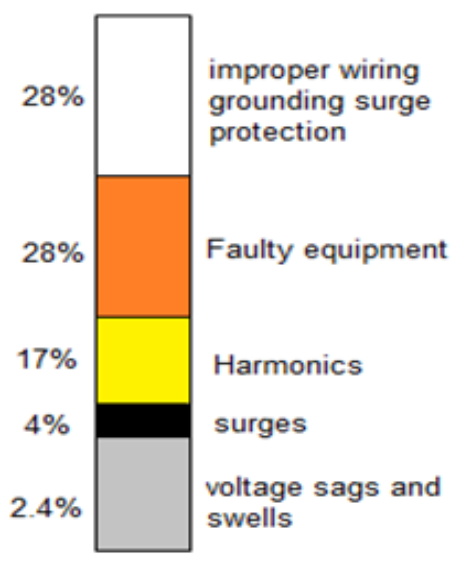

(a)

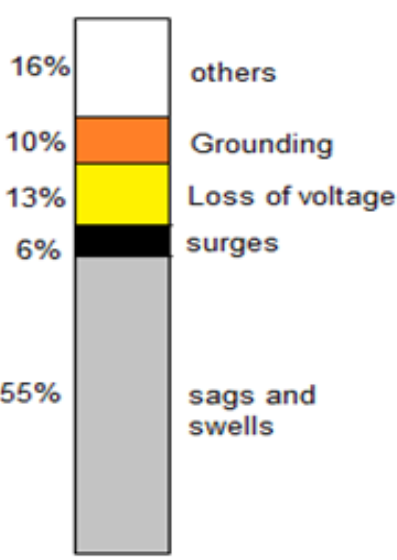

(b)

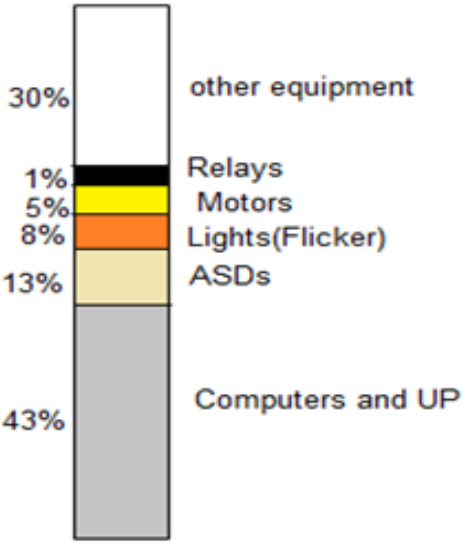

(c)

Fig.1 Basic disturbances: (a) Causes at customer side.

\section{(b) Causes at utility side. (c) Affected equipment}

A large number of quipment's that consists of power electronics devices are used by the industrial, commercial and residential customers at their installations, these equipment's are sensitive to power quality disturbances. the studies and the surveys in different countries around the world have been noticed that industries are vulnerable to reliability issue (long and short interruptions). The Voltage sag is the main power quality problem for the manufacturing industries and telecom sectors. Harmonics problems are perceived especially by the service sectors such as hospitals and banks. In $[2,3]$ another survey has been shown that the main problem For the continuation of industries are: loss of synchronization of processing devices, the tripping of relays and contactors without overloading and damaged computers and electronics devices. Also it has been noticed that the main problems of the power quality disturbances in service and transport sectors are: circuit breaker, damaged electronics equipment's and Lights flicker, blink or dim. All these surveys are shown in the Fig.2.

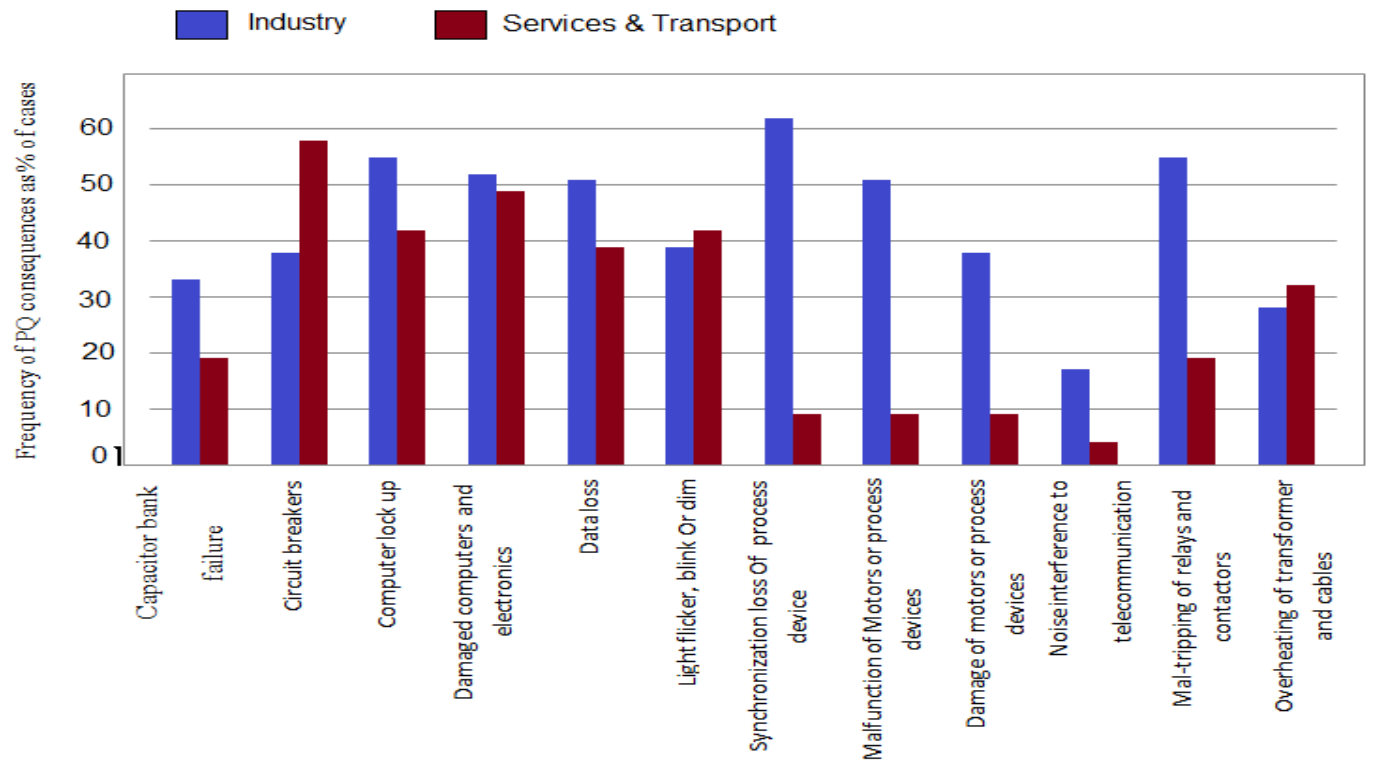

Fig.2 Consequences of poor $\mathrm{PQ}$ as experienced by the customers $[3,4]$

\section{2. -CLASSIFICATION OF POWER QUALITY PROBLEM}

Power quality is a combination of voltage and current quality. In most cases the utility is responsible for voltage quality at the point of common coupling (PCC) while the consumers often influence the current quality at the PCC[4,5]. There is always a relationship between the voltage and the current in any practical power system[ 6 ] . according to the IEEE definitions from IEEE standard 1159-1995[7] fig.3 shown the demarcation of various power quality problems. 


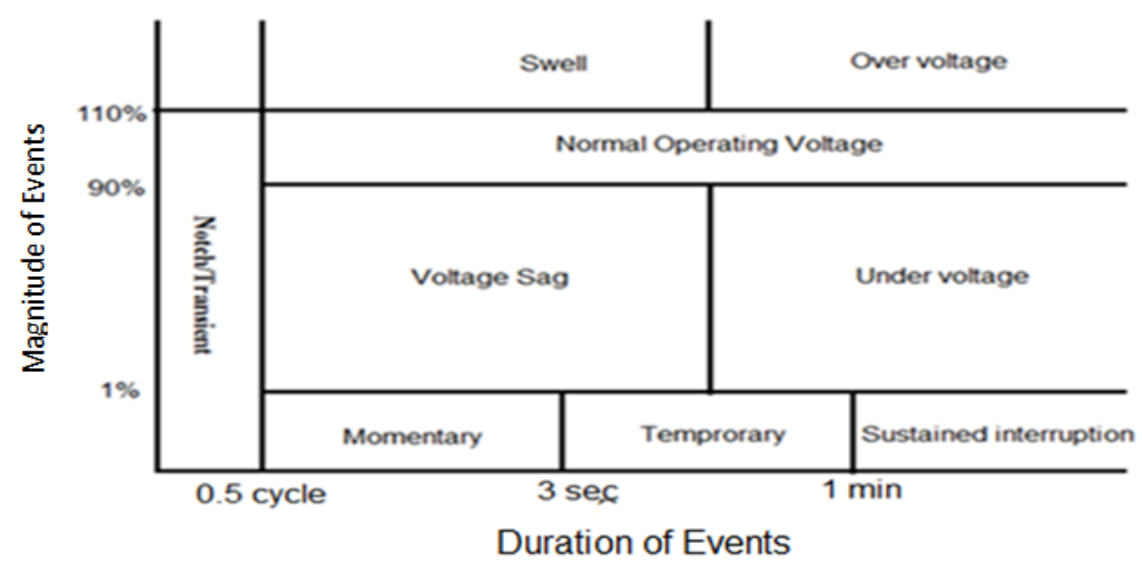

Fig.3 Voltage disturbances

Another survey is shown in fig. 4 we can conclude from this figure that the voltage sag ,harmonics and asymmetrical voltage are the most common power quality problems in the industrial process.

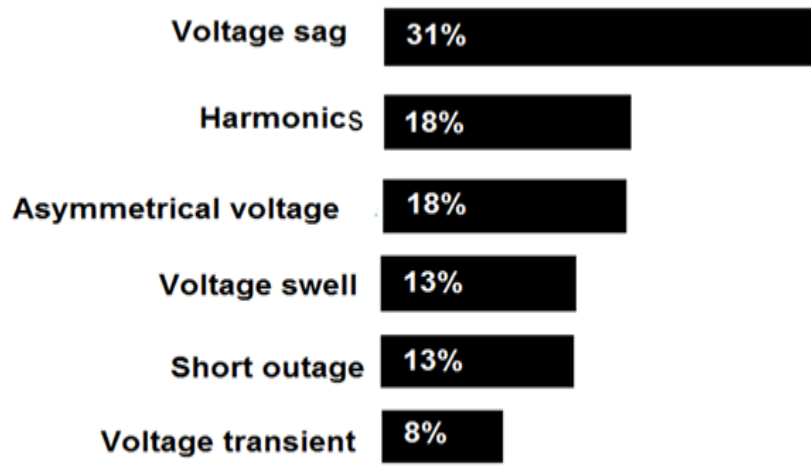

Fig.4 Power quality problems classification

\section{POWER QUALITY PROBLEMS}

i) Voltage sags:

A voltage sag is a sudden decrease in the r.m.s voltage that the voltage value become between 0.1 and 0.9 p.u. from its nominal value, and lasting from 0.5 cycle to several seconds.

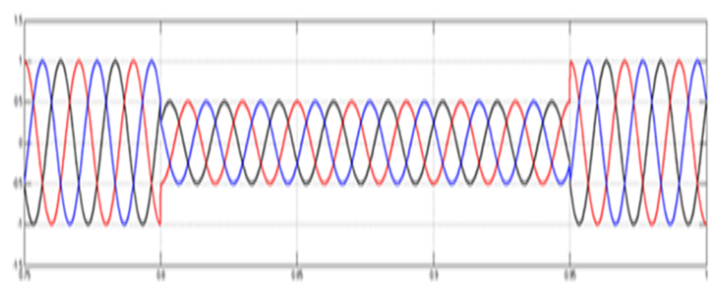

ii)

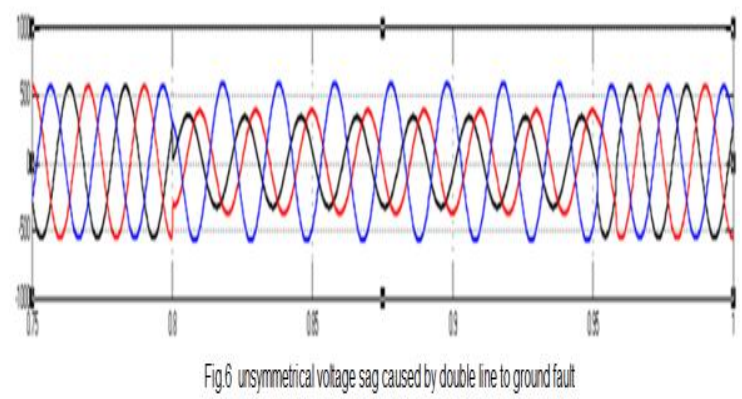

Sags with duration of less than a 0.5 cycle are considered as transients. Voltage sag either symmetrical or unsymmetrical as shown in figures.5,6,7.

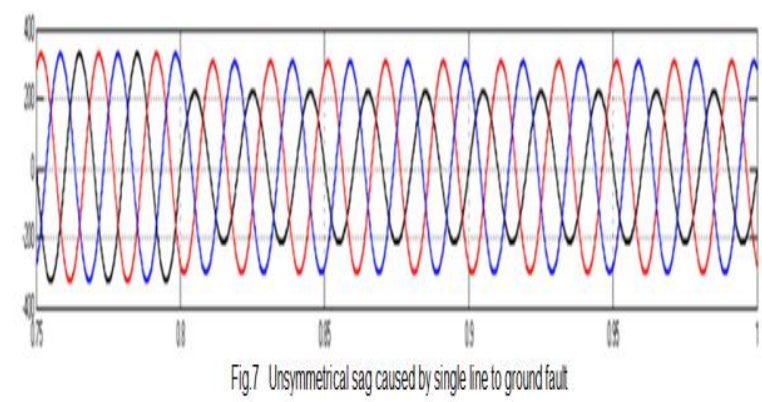

ii)Harmonics

Harmonics can be defined as the spectral components at frequencies that are integer multiples of the fundamental frequency. 

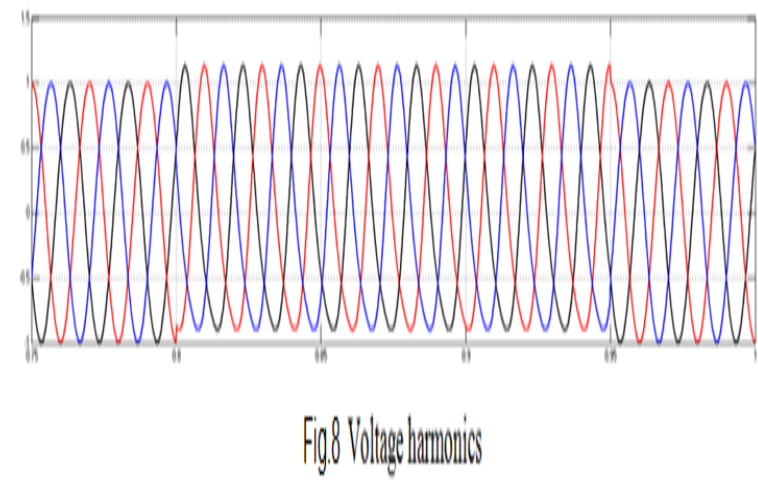

In fig. $62^{\text {nd }}$ order and $3^{\text {rd }}$ order harmonics are presence with the fundamental frequency waveform. It looks distorted as shown in Fig.6 The main cause to harmonic voltage distortion is the nonlinear loads.

Also There are several factors that contributing to the voltage harmonics such as:

- The voltage generated by a synchronous machine is not exactly sinusoidal due to small deviations from the ideal shape of the machine.The power system transmitting the electrical energy from the generation stations to the load is not completely linear. For example is the power transformer, where the non-linearity is due to saturation of the magnetic flux in the iron core of the transformer.

- Modren example of a non-linear power system component is the high voltage direct current (HVDC) link. The transformation from AC to DC and back takes place by using power-electronics components which only conduct during part of a cycle.

The most common harmonic current drawn non-linear loads are all single and three phase power converters which contain rectifiers such as DC motor drives, Adjustable speed drives (ASD), Uninterruptable Power Supplies (UPS), Switched mode power supplies (SMPS), fluorescent lighting, electrical heating furnaces, welding machine, arc furnaces. Besides these non-linear loads, AC generator, AC motors and transformers also produce harmonic currents. The effects of harmonics include harmonic heating and torque pulsation . These effects ultimately result in damage to the equipment. Transformers and other industrial equipment are more susceptible to harmonics. Harmonics voltage distortion can lead to control errors and malfunction of equipment. This can especially be a big problem in industrial power systems, where there is a large concentration of distorting load as well as sensitive load[10].

iii) iii) Swell:

A voltage swell is a sudden increase in the rms voltage between 1.1 and $1.9 \mathrm{pu}$ at the point in the electrical system, and lasting for 0.5 cycle to several seconds. Swells with duration of less than a cycle are regarded as transients.Fig.9 shows a waveform depicting a voltage swell

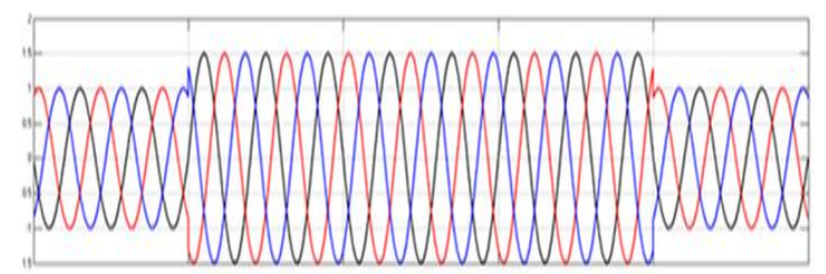

Fig.9 Voltage strell

\section{iv) Voltage interruption:}

The voltage is decreased to less than $0.1 \mathrm{pu}$ for a period not exceeding $1 \mathrm{~min}$.

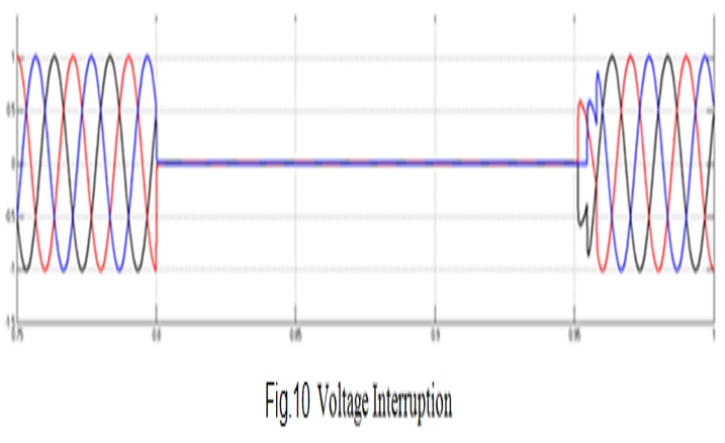

Transient:

Transient is a sudden change in steady state condition of voltage, current or both.

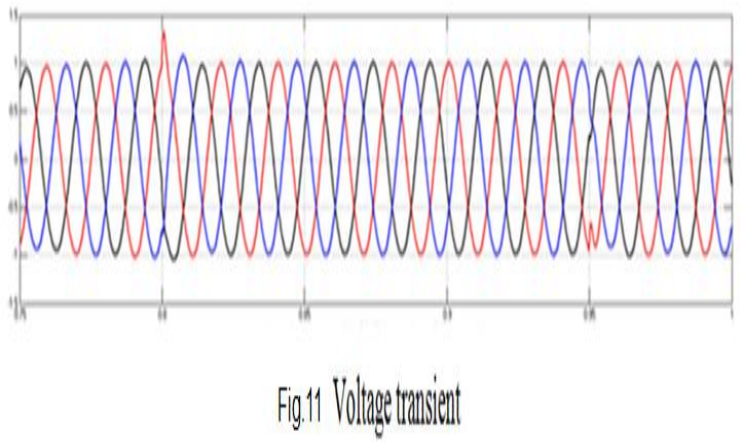

\section{EFFECTS OF VOLTAGE SAGS}

The problem of sag voltage is the most serious problem among the problems of power quality, where it leads to the flow of high current and thus damage sensitive devices such as: Computers, Programmable Logic Controller (PLC), Controller Power Supplies, Adjustable Speed Drives (ASD), Motor Starter Contactors.

The voltage sag problems in industrial equipment include[9]

- $\quad$ Relays opening without overloading, because of the sag affecting the relay's coil voltage.

- Sensor voltage gives incorrect reports, such as water pressure sensors or air flow sensors.

- Circuit breaker or fuses operating, due to the large increase in current immediately after the sag.

\section{CAUSES OF VOLTAGE SAG:}

i) Voltage sag due to faults

Voltage sags are mostly because of the power system faults. The severity of sag depends on the type of fault and the distance from the source and the fault, A three-phase fault near a distribution substation leads to all the customers connected to these substation will face deep sag[8]. The main reasons for power system fault are: weather (snow, wind, lightning) and interference from smaller animals and birds.

ii) Reclosure of circuit breaker

Operation of a circuit breaker or reclosure causes a temporary fault of a specific line. In case of weak grid, voltage sag in the neighboring lines will be occurred because 
of this temporary fault. The extent of the voltage sag is determined by distance from fault and supply voltage

\section{iii) Energizing the transformer}

The medium voltage line contains many transformers. When operating this line, these transformers energize at the same time, which leads to a very high current flow. This causes the voltage drop for a short period. This drop is the voltage sag and its effect is obvious to consumers

\section{iv) Starting of Induction Motor}

Induction motors take a very high current in starting up about greater than five to six times the nominal value taken by the motor. This high current remines until the induction motor starts running with the nominal speed. The voltage drop depends on specifications of power system and the induction motor.

\section{VOLTAGE DISTORTION LIMITS IEEE}

The voltage harmonic distortion limits apply to the quality of the power. For instance, for systems of less than $69 \mathrm{kV}$, IEEE 519 requires limits of 3 percent harmonic distortion for an individual frequency component and 5 percent for total harmonic distortion.

\section{Table1: Voltage distortion limits for harmonics}

\begin{tabular}{|c|c|c|}
\hline Bus voltage & Individual $V_{b}(\%)$ & $\operatorname{THDV}(\%)$ \\
\hline $\mathrm{V}<69 \mathrm{kV}$ & 3.0 & 5.0 \\
\hline $69 \leq \mathrm{V}<161 \mathrm{kV}$ & 1.5 & 2.5 \\
\hline $\mathrm{V} \geq 161 \mathrm{kV}$ & 1.0 & 1.5 \\
\hline
\end{tabular}

\section{POWER QUALITY IMPROVEMENT TECHNIQUES AND SOLUTIONS:}

power quality problems can be defined as the difference between the quality of power supplied and the quality of power required for reliable operation of the load equipment. Several types of power enhancement devices have been developed over the years to protect equipment from power disturbances. Some of the effective and economic measures can be identified as following:

i Power conditioning devices

ii Custom power devices

iii Power conditioning devices

1. Lightning and surge arrestors : Arrestors are using to protect The transformers from lightning and voltage surges but are certainly not sufficient for limiting voltage disturbances to protect sensitive electronic circuits from voltage surges.

2. Transient Voltage Surge Capacitors (TVSC): These units clamp spikes to a level that it is safe for the sensitive loads. Employing an entire facility protection strategy will safeguard the electrical system against most transients.

3. Filters: Provide protection against high frequency low voltage noises. Filters are designed to pass the fundamental frequency and reject the higher frequency noise such as electromagnetic interference (EMI) and ratio frequency interference (RFI). Harmonics filters prevent the harmonics content of non linear loads from back to the power source.

4. Isolation transformer: Provides a degree of filtering and isolation. Isolation transformers reduce electrical noise by separation of the primary and secondary through magnetic isolation. Isolation transformer reduce noises and harmonics but it does not compensate for power outages and voltage fluctuations

5. Voltage RegulatorsVoltage regulators maintain output voltage at nominal voltage under severe input voltage variations. There are three basic types of regulators:

(i) Tap changing Transformer: Designed to adjust for varying voltages by automatically transferring taps on a power transformer. The main advantage of tap changers is high efficiency, wide input range, high over load current capability and good noise isolation compared to other voltage regulation technology. Disadvantages are noise created when changing taps and no waveform correction. The tap-changing transformer is: slow in response, exhibits contact erosion needs routine maintenance of its parts, has an uneconomical size and requires frequent replacement of transformer oil[11]

(ii) Buck boost: Utilizes similar technology to the changers except the transformer being not isolated. One of the advantages is that it can withstand high in-rush currents. Disadvantages are noise created when changing taps, poor noise isolation and no waveform correction

(iii) Constant Voltage Transformer (CVT): It is also known as Ferro resonant transformer. The CVT is a static regulator that maintains a nearly constant output voltage during large voltage variations in the input voltage. Advantages are superior noise isolation, very precise output voltage and current limiting for overload protection. The lack of moving parts means that the transformer requires little maintenance. Disadvantages are large size, audible noise and low efficiency.

\section{UNINTERRUPTIBLE POWER SUPPLY (UPS)}

UPS systems provide protection in the case of a complete power interruption. There are three major UPS topologies each providing different levels of protection : off-line UPS, Line interactive UPS and on-line UPS. Topology may be considered according to the load requirement based on efficiency, cost and transfer time. Moreover, UPS also requires a high level of maintenance because of, leakage of batteries and also needs replacement for every five years.

\section{CUSTOM POWER DEVICES}

Customers are demanding electrical power with high quality from the electric utilities. Custom power devices are capable to solve power quality problems. The concept of custom power is based on the use of power electronic controllers in the distribution system for the purpose of providing reliable and high quality power that is needed by sensitive equipments to power quality variations.

\section{Types of Custom Power Devices}

There are two major categories of custom power devices:

1. network reconfiguring type

2. compensating type 
1. network reconfiguring type(switchgear) which used for power quality enhancement and these include: Static current Breaker(SCB), Static current limiter(SCL) and Static Transfer Switch (STS).

(i) Static Current Limiter (SCL):

SCL limits a fault current by quickly inserting a series inductance in the fault path. It consists of a pair of antiparallel gate turn off thyristors switch with snubbers (RC circuit) and a current limiting inductor. The currents limiter is connected in series with a feeder such that it can restrict the current in the case of a fault downstream. In the healthy state, the opposite poled switch remains closed. These switches are opened, when a fault is detected, such that the fault current now flows through the current limiting inductor[8]

(ii) Static Circuit Breaker (SCB):

SCB breaks a faulted circuit much faster than a mechanical circuit breaker. An SCB has almost the same topology as that of an SCL except that the limiting inductor is connected in series with an opposite poled thyristor pair. The Gate Turn Off thyristor (GTO) are the normal current carrying elements. The thyristor pair is switched on simultaneously as the bidirectional switch GTO is switched off once a fault is detected. This will force the fault current to flow through the limiting inductor. The Thyristor pair is blocked after a few cycles if the fault still persists. The current through the thyristor pair will case to flow at the next available zero crossing of the current[8].

(iii) Solid-State Switch Based on The Thyristor Device (STS):

The properties of a thyristor (ON- state and OFF-state) are used to perform an intelligent switch which can choose between two power sources and provide the best available

\section{SIMULATION AND RESULTS:}

power to the electrical load [9]. In most cases the STS is capable to limit the duration of voltage sags and interruptions to less than 0.5 cycle by transferring the loads from the affected feeder to a backup feeder. STS response is very high speed [14] but when both the feeders are affected by voltage disturbances STS become not suitable

2. compensating type[12] which used for voltage regulation, Power factor correction, load balancing and active filtering. Compensating type are include: Distributed Static Compensator (DSTATCOM), Dynamic Voltage Restorer (DVR) and Unified Power Quality Conditioner (UPQC).

i) Dynamic Voltage Restorer:

DVR is a compensating custom power type device. Voltage Source Inverter (VSI) of DVR generates a compensating voltage, which is then injected in the distribution system by means of series injection transformer. Passive filter connected between the VSI and the injection transformer, eliminates the higher order harmonic components from the inverter output voltage. Energy storage device connected to the VSI provides the necessary active power for the compensation[14]. DVR compensation ability depends on the range of sags and size of the energy storage.

ii) DSTATCOM:

Shunt devices are effective to compensate small voltage variation, which can be controlled by reactive power injection. The ability to control the fundamental voltage at a certain point depends on the impedance to the supply and the power factor of the load. The compensation of a voltage dip by current injection is very difficult to achieve, because the supply impedance is usually low and the injected current has to be very high to increase the load voltage.

1-Without custom power devices

Fig.12 shows the Simulink model of the test system in which the two parallel feeders are cleared

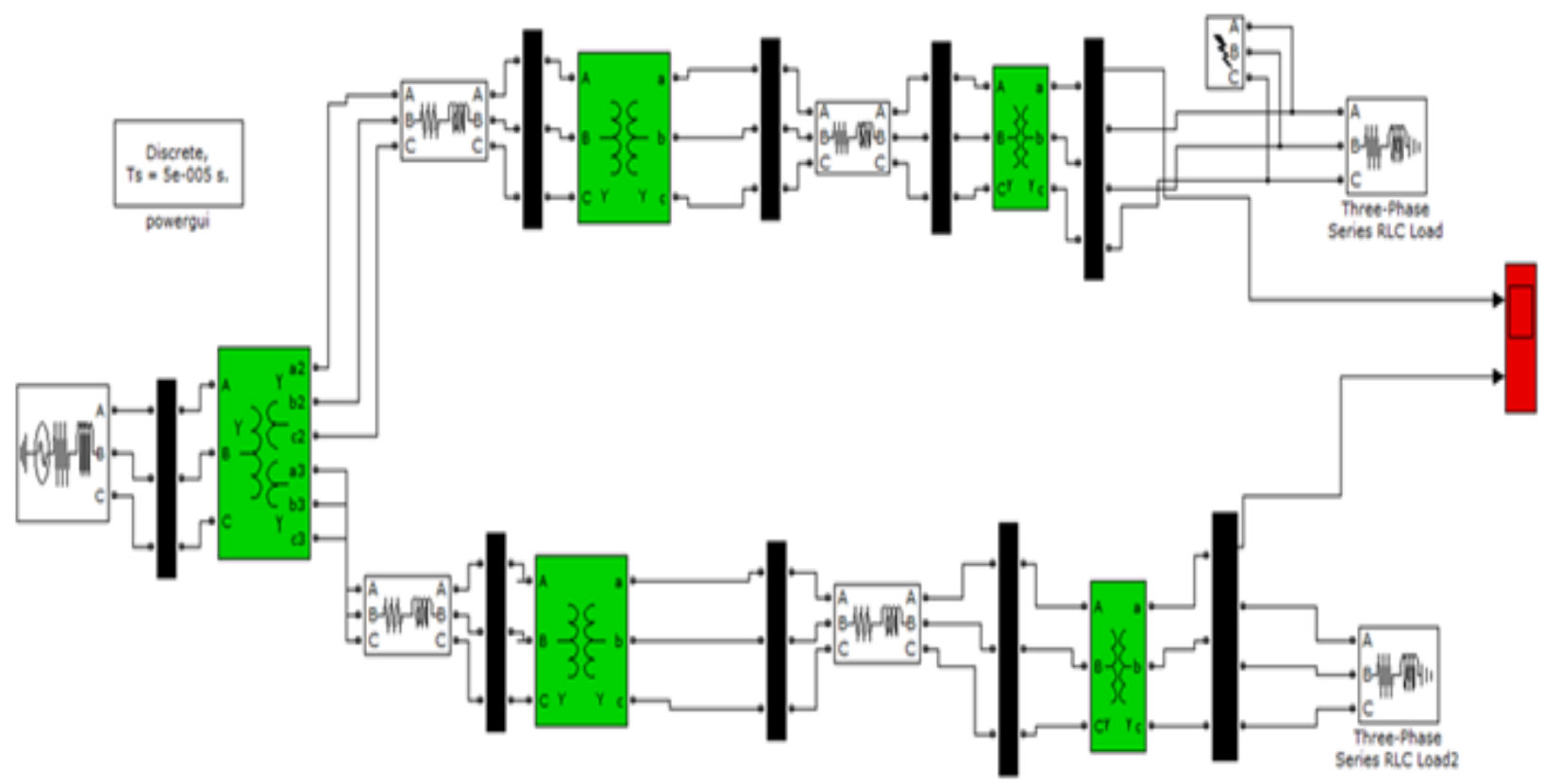

Fig.12 Simulink model of test system without custom power device 
i)Three phase to ground fault

In this test a three phase to ground fault is introduced in the first feeder. Here the fault resistance is $(0.001 \mathrm{ohms})$ and the ground resistance is $(0.001 \mathrm{ohms})$. The total fault duration is
$0.15 \mathrm{sec}$ from $0.8 \mathrm{~s}$ to $0.95 \mathrm{~s}$ as shown in fig.13. Symmetrical sag is occurred automatically at adjacent feeder as seen in fig. 14

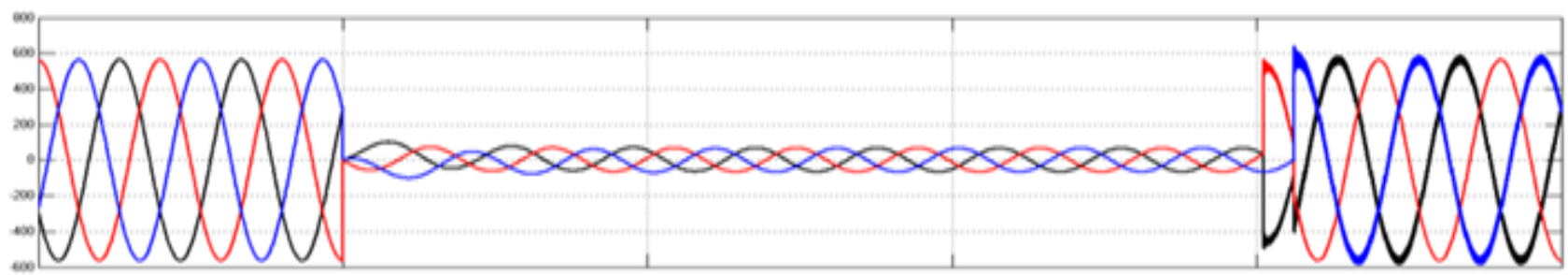

Fig.13 Load voltage at the feeder where the three phase to ground fault occurred

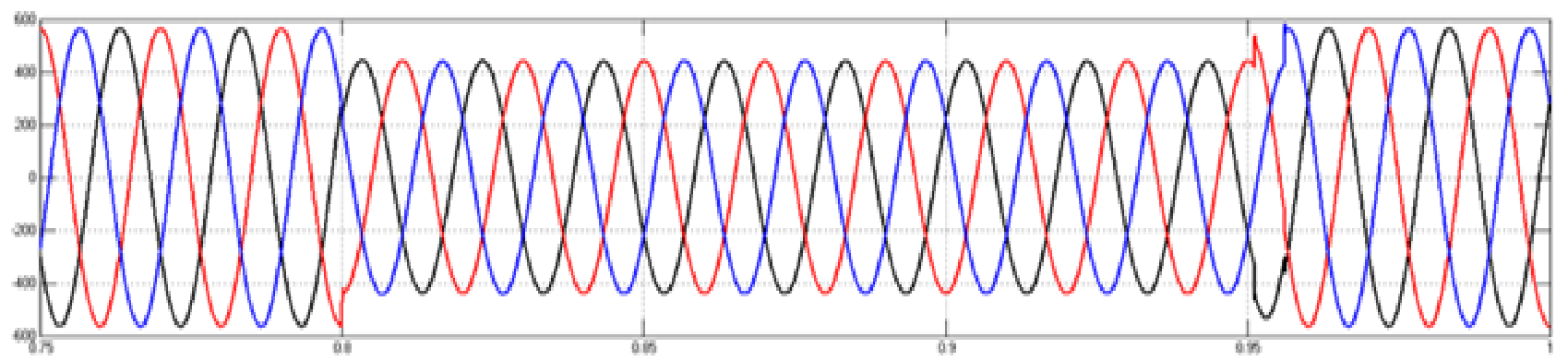

Fig.14 Load voltage at adjacent feeder

ii)Double line to ground fault:

As shown in fig. 15 double line to ground fault is simulated, the fault resistance is $(0.001 \mathrm{ohms})$ and the ground resistance is ( $0.001 \mathrm{ohms})$. The total fault duration is $0.15 \mathrm{~s}$ from $0.8 \mathrm{~s}$ to
$0.95 \mathrm{~s}$ as can seen in fig. 15 . Asymmetrical sag is occurred automatically at adjacent feeder as shown in fig. 16 .

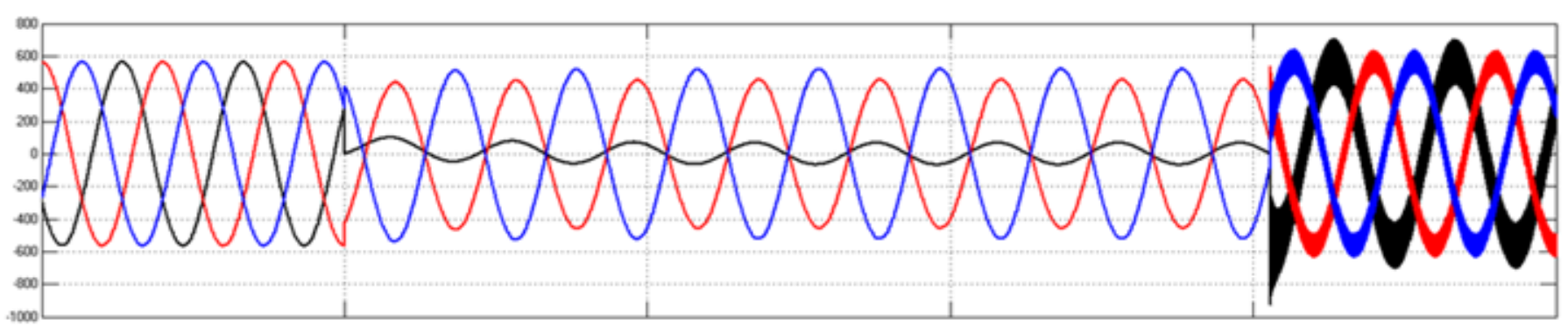

Fig.15 Load voltage at the feeder where single line to ground fault occurred

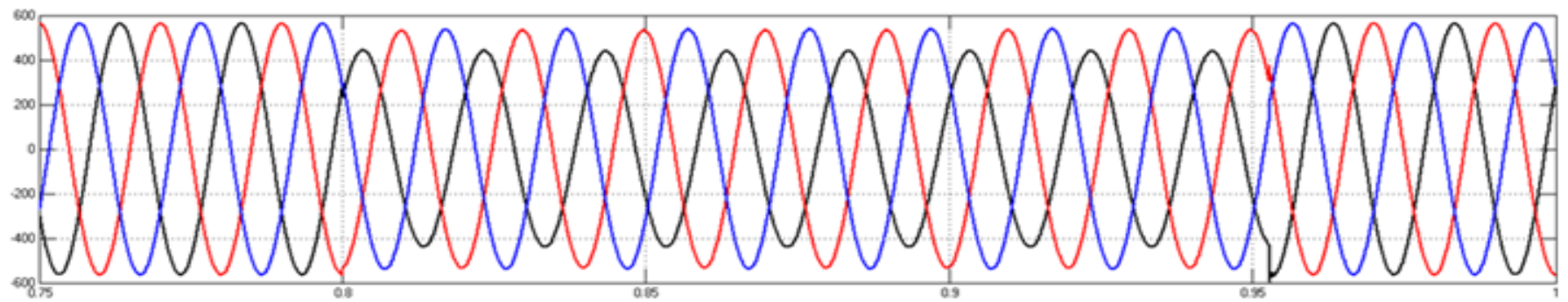

Fig.16 Load voltage at adjacent feeder

2- With custom power device

Fig.17 shows the simulink model of the test system in which Dynamic Voltage Restorer(DVR) is connected at the second feeder 


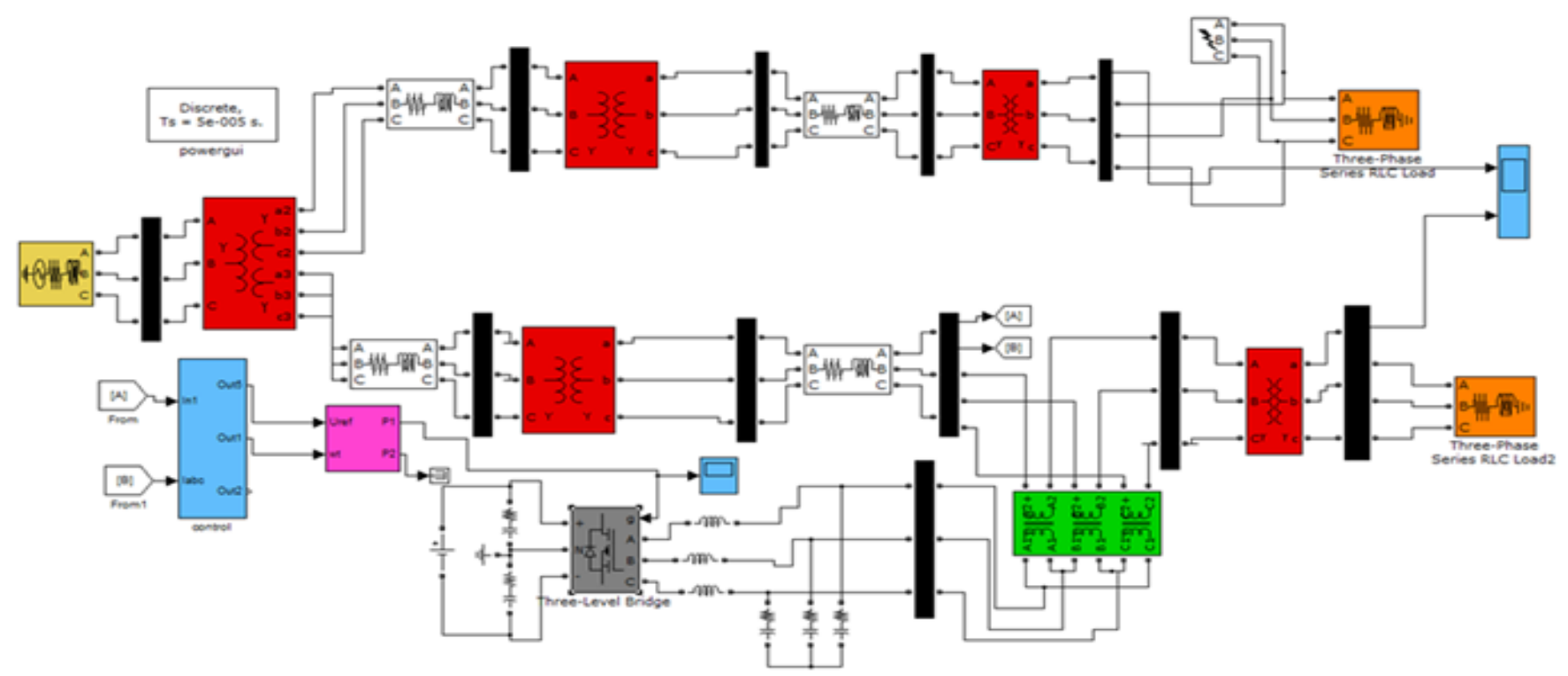

Fig.17 Simulink model of test system with custom power device

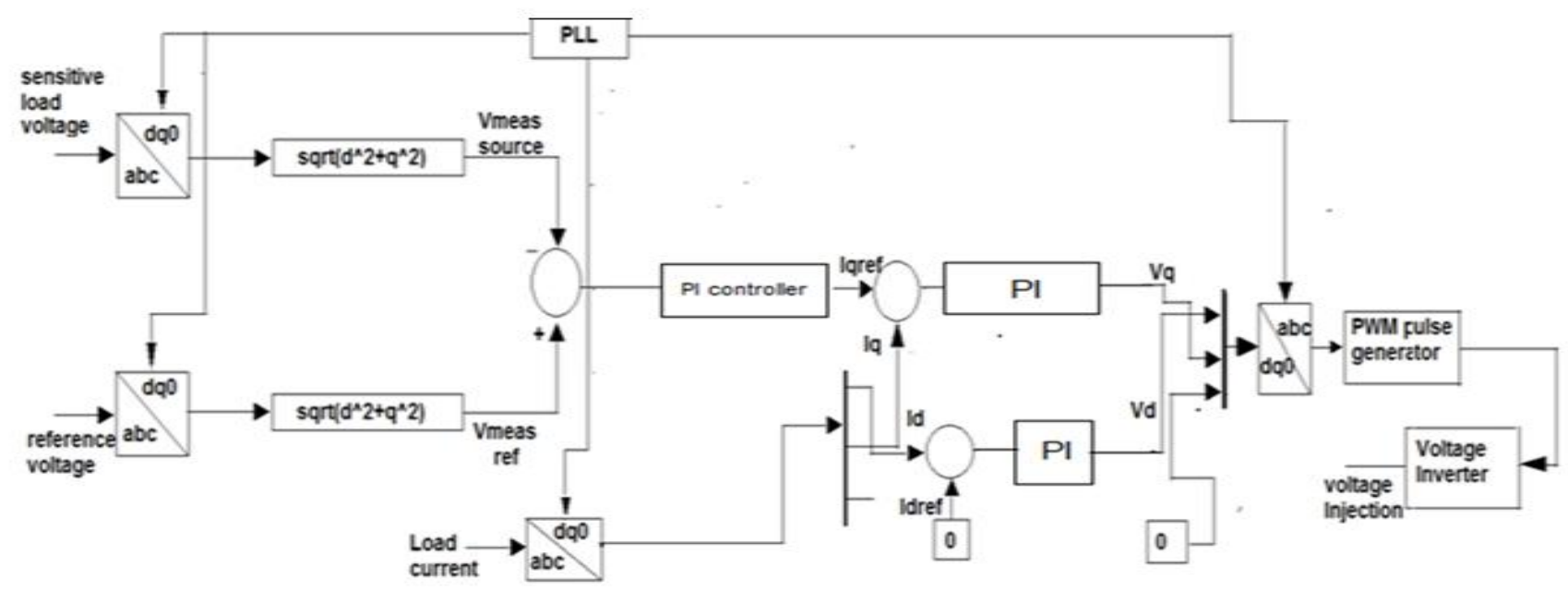

Fig.18 Block diagram of the DVR control unit

i) Three phase to ground fault

Custom power devices at the second feeder is restored the load voltage to the pre-sag value as shown in fig.19

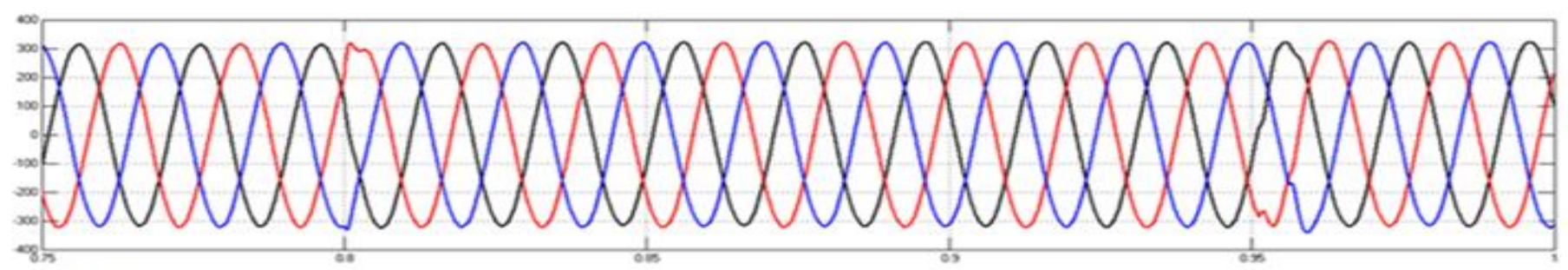

Fig.19 Load voltage during three line to ground fault for the adjacent feeder with custom power device ii)Double line to ground fault

Fig.20 shown the load voltage at the second feeder. As can seen that the custom power device is capable to restore the load voltage to its nominal value 


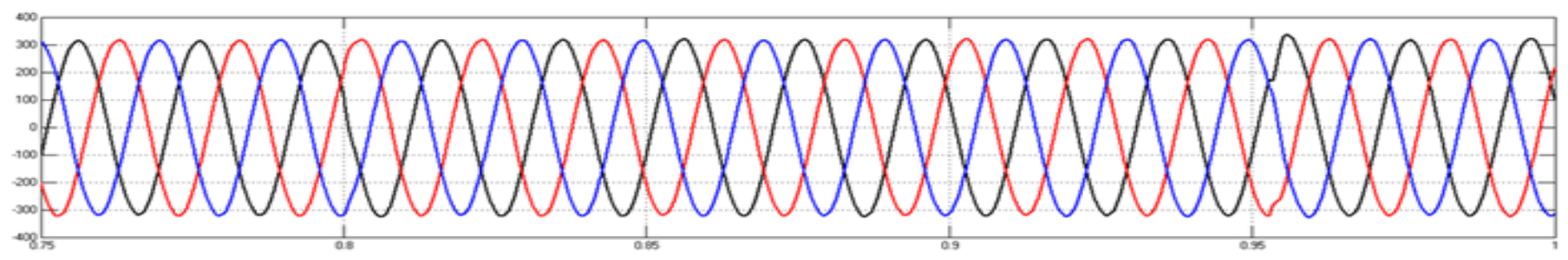

Fig.20 Load voltage during single line to ground fault for the adjacent feeder with custom power

\section{CONCLUSIONS:}

With the increasing use of sensitive loads, power quality problems such as voltage sags, swells, flickers and harmonics are introduced into the distribution system. Voltage sag and harmonics are most common power problems in the industrial sectors. Loss of synchronization of processing equipment and lock ups of computer is a severe problem for continuous manufacturing industries. Circuit breakers tripping and data loss is the main problem caused by poor power quality in the service and transport sectors. The FACTS devices are used to improve the power transfer capabilities and stability margins of the transmission line. The custom power devices are effective to restore the sensitive load voltage to the pre-fault value and make it smooth under different cases of faults and nonlinear load condition. Some of these custom power devices include: DSTATCOM, UPQC, and DVR etc. Among these Dynamic Voltage Restorer (DVR) which is series connected power electronic based device is one of the most efficient and effective custom power devices to protect the sensitive equipments against voltage sags and harmonics due to its lower cost, smaller size and dynamic response. The simulation results showed that the load voltage was compensated fully within the permissible THD limit with the help of the Dynamic Voltage Restorer which is one of the custom power devices types.

\section{REFERENCES}

[1] Pandu Sathish Babu Nagappan Kamaraj, 'Quality Enhancement using Dynamic Voltage Restorer', Lambert Academic Publishing, chapter-1, pp.1-16.

[2] Manson, J \& Targosz, R2008, 'European power quality survey report Leonardo Energy', www.leonardoenergy.org.

[3] Bhattacharyya, S \& Cobben, S 2011, 'Consequences of poor power quality - An overview', Available from: http://www.intechopen.com/books/powerquality/consequences-of-poor-power-quality-anoverview.

[4] Bhattacharyya, S, Myrzik, JAM, Cobben, JFG, Kling, WL \& Didden, M 2007, 'Need of voltage quality regulation in the future electricity
[5] infrastructure', Ninth international conference on electrical power quality and utilization, pp. 1-6.

[6] Bollen, MHJ 2001, 'Understanding power quality problems-voltage sags and interruptions', IEEE Press series on power Engineering, NewYork

[7] Pohjanheimo,P 2003, ' A probabilistic method for comprchensive voltage sag management in power distribution systems',Ph.D.thesis, Aalto University School of Science and Technology.

[8] Singh, BN \& Simina, M2004, 'Intelligent solid-state voltage restorer for voltage swell/sag and harmonics electric power applications' Proceeding of IEE on Electric Power Application, vol. 151,no. 1,pp.98-106.

[9] Ghosh, A \& Ledwich, G 2002, 'Power quality enhancement using custom power devices', Kluwer Academic Publishers.

[10] Bhanoo, MM \& Mentor, OH 1998,'Static transfer switch: Advances in high speed solid-state transfer switches for critical power quality and reliability applications', Proceedings of IEEE Textile, Fiber and Film Industry Technical Conference, vol.5,pp. 1-8.

[11] Chan, K, Kara, A, Dachler, P \& Tinggren, R 1999, 'innovative system solutions for power quality enhancement,' Proceedings of CIRED fifteenth international conference on Electricity distribution, pp. $1-8$.

[12] Woodley, N, Morgan, L \& Sundaram, A 1999, 'Experience with an inverter-based dynamic voltage restorer', IEEE Transactions on Power Delivery, vol. 14,no.3,pp.1181-1186.

[13] Pandu Sathish Babu Nagappan Kamaraj, 'Quality Enhancement using Dynamic Voltage Restorer', Lambert Academic Publishing, chapter-2, pp.22-29

[14] Haque, MH 2001, 'Compensation of distribution system voltage sag by DVR and D-STATCOM', Proceedings of IEEE Conference on Power Technology, vol. 1, pp.1-5

[15] Bongiorno, M, Sannino, A \& Dusonchet, L 2003, 'Costeffective power quality improvement for industrial plants', Proceedings of IEEE international conference on power technology, Bologna, vol. 4, pp. 1-6. 